Case report

\title{
Multiple, genital lobular capillary haemangioma (pyogenic granuloma) in a young woman: a diagnostic puzzle
}

\author{
Somesh Gupta, Bishan Dass Radotra, Bhushan Kumar
}

A 21 year old woman presented with multiple lobulated lesions on the labia majora. The surface of most of the lesions was ulcerated revealing a glistening surface. All lesions were excised. The histopathology revealed features suggestive of lobular capillary haemangioma (pyogenic granuloma). Pyogenic granuloma is considered as a reactive hyperproliferative vascular response to trauma or other stimuli. A literature search revealed reports of a few cases of lobular capillary haemangioma of the glans penis but not on the female genitalia. This case is presented to help physicians become aware that lobular capillary haemangiomas (pyogenic granuloma) may occur at this site.

(Sex Transm Inf 2000;76:51-52)

Keywords: pyogenic granuloma; vulva

\section{Case report}

A 21 year old unmarried woman presented with pedunculated lesions around the lower aspect of the labia majora. About 6 years earlier she had developed a generalised maculopapular rash associated with fever and itching, which subsided with some treatment (which was not known), leaving behind transient hyperpigmentation. However, a few lesions on the vulva became slightly elevated and later pedunculated which persisted for 3 years and then subsided without treatment. About 2 months later, she again developed similar lesions, which had persisted. The lesions were asymptomatic except that they bled occasionally. She categorically denied any kind of sexual exposure at any time. There was no history of any trauma other than that caused by itching.

Examination revealed multiple, large, papillomatous cherry-like red lesions in groups on the left labia majora (Fig 1). The skin was ulcerated over most of the nodules, revealing a glistening red surface. Some smaller papular lesions were also seen on the adjacent skin. The tissue smear and Gram smear from the \begin{abstract}
ulcerated surface of the nodules did not reveal any organisms. Dark ground illumination for

Dermatology,

Venereology and
\end{abstract}

Department of

Leprology,

Postgraduate Institute

of Medical Education

and Research,

Chandigarh, India

S Gupta

B Kumar

\section{Department of \\ Pathology}

B D Radotra

Correspondence to: Dr Bhushan Kumar,

Department of Dermatology, Venereology and Leprology, PGIMER, Chandigarh-160 012 , India

Accepted for publication 5 November 1999

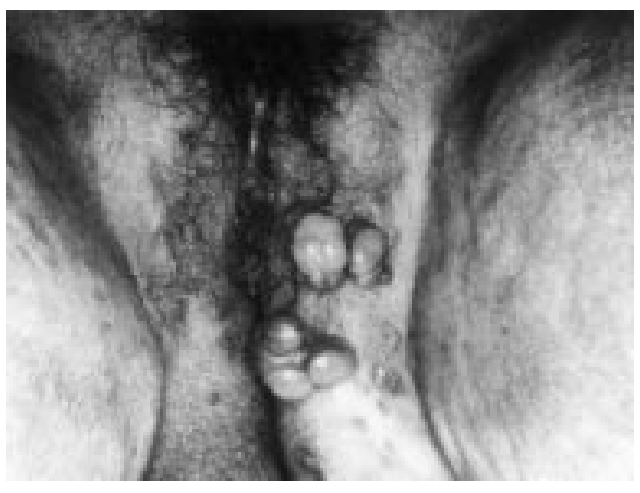

Figure 1 Multiple lobular capillary haemangioma on labia majora. Note ulceration over surface of the lesions revealing glistening red surface.
Treponema pallidum was also negative. Serology for syphilis and HIV and haematological and biochemical investigations were not contributory. All lesions were excised and sent for histopathological examination, which revealed a polypoidal structure with extensive proliferation of vascular channels lined by a single layer of endothelium (Fig 2). The intervening stroma consisting of collagen was infiltrated by lymphomononuclear cells. The histopathological features were consistent with lobular capillary haemangioma. There was no noticeable recurrence until 2 months after the excision.

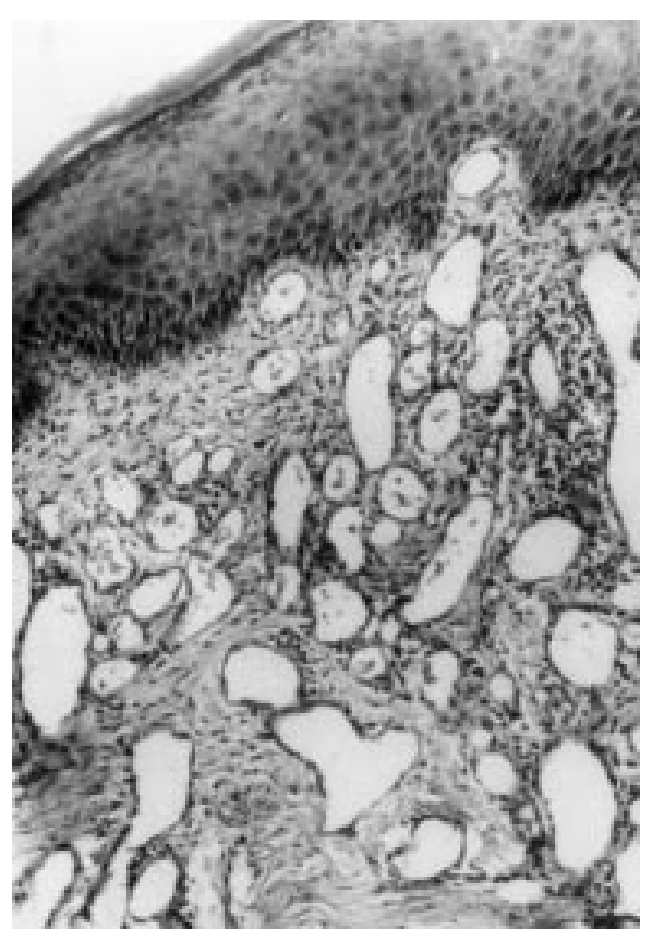

Figure 2 Numerous vascular channels lined by a single layer of endothelium with intervening inflammatory cells. 


\section{Discussion}

Lobular capillary haemangioma or pyogenic granuloma usually presents as a solitary, lobulated, pedunculated, or sessile benign growth over the face, arms, or hands. ${ }^{1}$ Its characteristic bright red colour and granulation tissue-like appearance is determined by integrity and thickness of the overlying epidermis and stage of the disease. In chronic lesions, these characteristic features may not be evident as observed in our patient. The aetiopathogenesis of pyogenic granuloma remains unclear. It has been considered as a reactive hyperproliferative vascular response to a variety of stimuli rather than a true haemangioma. ${ }^{1}$ Excessive local production of tumour angiogenesis factor as a consequence of minor trauma or underlying cutaneous disease might be an important factor in the pathogenesis of pyogenic granuloma. ${ }^{2}$ Various cutaneous pathologies, which have been reported to be associated with pyogenic granuloma are portwine stain, insect bite, localised viral infections, psoriasis, eczema, burns, erythroderma, and cutaneous changes due to retinoid therapy. ${ }^{2}{ }^{3}$ As the nature of pruritic disease, which precipitated the pyogenic granuloma in the present patient, is not known, we are not sure whether the disease itself or excoriation trauma was the stimulus for angiogenesis. We did not find evidence of any underlying disease in histopathological examination.

A literature scan revealed a few cases of pyogenic granuloma involving the male genitalia. ${ }^{4-7}$ However, a literature search (using Medline) has revealed no previous reports of pyogenic granuloma involving the female genitalia. This might in the past have discouraged clinicians from making this diagnosis when it was appropriate to do so. Another atypical feature in the present case was presence of multiple pyogenic granuloma, for pyogenic granuloma usually occurs as a single lesion. Multiple eruptive pyogenic granuloma can occasionally occur after excision. ${ }^{1}$ However, multiple pyogenic granuloma in a non-eruptive form or in the absence of some other underlying cutaneous pathology (for example, erythroderma, burn) are very rare. ${ }^{8}$

Unfamiliarity with these types of lesions on the vulva can cause confusion with other common polypoidal morphologies of this site such as warts, bowenoid papulosis, giant condylomas, and verrucous carcinoma. Raised papules resembling pyogenic granuloma can also occur in acquired tufted angioma, Kaposi's sarcoma, epithelioid haemangioendothelioma, and bacillary angiomatosis, but can easily be differentiated by histopathology. ${ }^{1}$ Small, elongated angiomatous aggregates referred to as tufts, in tufted angiomas ${ }^{1}$; spindle cell proliferation and extravasation of red cells in Kaposi's sarcoma ${ }^{9}$; epithelioid cells in epithelioid haemangioendothelioma; and neutrophils, nuclear dust, and bacterial colonies in bacillary angiomatosis, ${ }^{9}$ are differentiating features which helped us in excluding these possibilities and in making a diagnosis of pyogenic granuloma confidently.

In conclusion, to the best of our knowledge, this report is the first documentation of a case of multiple pyogenic granuloma on the labia majora and makes the physician aware of this benign proliferative disease at this site.

Contributors: SG did the clinical study, planning, and execution; BDR performed the histopathological study; and BK did the clinical study, planning, and execution.

1 Requena L, Sangueza OP. Cutaneous vascular proliferations. Part II. Hyperplasias and benign neoplasms. 7 Am Acad Dermatol 1997;37:887-919.

2 Patrice SJ, Wiss K, Mulliken JB. Pyogenic granuloma (lobular capillary hemangioma): a clinicopathologic study of 178 cases. Pediatr Dermatol 1991;8:267-76.

3 Ceyhan M, Erdem G, Kotiloglu E, et al. Pyogenic granuloma with multiple dissemination in a burn lesion. Pediatr Dermatol 1997;14:213-15.

4 Tomasini C, Puiatti P, Bernengo MG. Multiple pyogenic granuloma of the penis. Sex Transm Inf 1998;74:221-2.

5 Walzman M, Kundu A, Fraser I. Pyogenic granuloma of the penis-a rare entity? Genitourin Med 1995;71:43-4

6 Maeda Y, Izutani T, Yonese J, et al. Pyogenic granuloma of the glans penis. Br F Urol 1998;82:771-2.

7 Summers JL. Pyogenic granuloma: an unusual complication of papaverine injection therapy for impotence. F Urol 1990; 143:1227-8.

8 Torres JE, Sanchez JL. Disseminated pyogenic granuloma developing after exfoliative dermatitis. $\mathscr{f} \mathrm{Am}$ Acad Dermatol 1995;32:280-2.

9 LeBoit PE. Lobular capilary proliferation: the underlying process in diverse benign cutaneous vascular neoplasm and reactive conditions. Semin Dermatol 1989;8:298-310. 